\title{
Health promoting lifestyle behaviors and related risk factors among female employees in Zagazig city
}

\author{
Amany Sobhy Sorour, Wagida Wafek Kamel, Eman Mohammed Abd El- Aziz, Amany Aboelseoud \\ Zagazig Univesity, Al Sharqiyah, Egypt. \\ Correspondence: Amany Sobhy Sorour. Address: Zagazig Univesity, Al Modir St, Markaz El-Zakazik, Ash Sharqiyah \\ 44516, Egypt. Email: amany_ss@hotmail.com
}

Received: November 22, 2013

Accepted: January 19, $2014 \quad$ Online Published: March 4, 2014

DOI : $10.5430 /$ jnep.v4n5p42

URL: http://dx.doi.org/10.5430/jnep.v4n5p42

\section{Abstract}

Aim of the study: This study aimed to measure health Promoting lifestyle behaviors and related risk factors among female employees in Zagazig City.

Subjects and Methods: A cross sectional research design was selected to achieve the aim of the current study. The study was carried out on females employed in the governorate building in Zagazig city.

Study participants: The study sample is a convenience sample of 200 females recruited from Zagazig Governorate administrative building. The inclusion criteria included females, aged 25 to 55, working in any administrative department for any duration and willing to participate in the study. The exclusion criteria were females not suffering from hypertension, diabetes mellitus.

Results: Results revealed that about one fifth of the studied sample (20\%) was hypertensive, while $26 \%$ and $68.5 \%$ respectively were diabetic and obese. No statistically significant relation between chronic illnesses (hypertension, diabetes and obesity) and healthy promoting lifestyle behaviors among study sample.

Conclusion: Results suggest that participants do not consistently include health-promoting behaviors into their lifestyle, especially exercise, health responsibility and stress management.

Recommendation: Develop a process to promote worksite wellness programs, to complete health assessments, and to support behavioral changes intended to promote healthy lifestyles.

\section{Key words}

Health promoting lifestyle, Female employee, Risk factors

\section{Introduction}

The most prominent aspect of the goals and strategies of the World Health Organization (WHO) in Health for All in 2000 was the emphasis on health promotion ${ }^{[1]}$. As part of the Project of Health for All, at the International Health Promotion conference, conducted in Ottawa, Canada, health promotion was defined as: a process in which people get to promote over their own health. All the efforts for accomplishing a healthy life can be considered as a Healthy Lifestyle. According to Pender, the healthy lifestyle behaviors are self-actualization, health responsibility, exercise, nutrition, interpersonal support and stress management ${ }^{[2]}$. 
Public health and clinical strategies for meeting the emerging challenges of multiple chronic conditions must address the high prevalence of lifestyle-related causes ${ }^{[3]}$. Chronic diseases have a serious impact on individuals and on society in general. They affect the quality of life of individuals and can be a financial burden on those who are affected ${ }^{[4]}$. More than $70 \%$ of deaths in the United States and about $75 \%$ of health care spending costs are attributed to chronic diseases ${ }^{[5]}$.

Chronic diseases were responsible for 50\% of the disease burden in 23 high-burden developing countries in 2005 and will cost those countries $\$ 84$ billion by 2015 if nothing is done to slow their growth. The rise of lifestyle-related chronic disease in poor countries is the result of a complex constellation of social, economic, and behavioral factors ${ }^{[6]}$.

The risk factors for chronic disease include overweight and obesity, physical inactivity, poor diet, smoking and excessive alcohol consumption. Adopting healthy lifestyle practices such as a healthy diet, regular physical activity, and quitting or avoiding tobacco use can prevent or control the onset of debilitating and expensive complications of chronic diseases ${ }^{[4]}$.

Promoting healthy lifestyle behavior in women, who are the keystones of a society, enables the achievement of healthy generations. Women are the caregivers of the family, and they are a keystone of utmost importance in promoting and maintaining family health in all cultures ${ }^{[7]}$ and thus it is important that women be physically, mentally and socially in good health.

Recently, considerable concern about job stress has given rise to a theoretical approach that focuses on a DemandControl-Support Model of job strain, as proposed by Karasek et al. ${ }^{[8]}$. This model predicts that job strain will occur when psychological work demands are high and the worker's job control is low: a low level of workplace social support will increase the risk of negative health outcomes. The psychological demand dimension relates to "How hard workers work" (mental work load), organizational constraints on task completion, and conflicting demands ${ }^{[8]}$. An understanding of the existing health-promoting lifestyles of female workers would be a benefit to health promotion practitioners when designing health promotion programs. Additionally, the relationship between the levels of perceived business in daily life and the practice of health-promoting behaviors has seldom been examined.

Primary health care providers such as GPs and practice nurses have a particularly important role in the identifying, assessing at risk patients and offering brief interventions and long term follow up. However, this is often insufficient, and more intensive education and support are required from a range of providers and services including community based programs ${ }^{[9]}$.

Therefore the study aimed to measure health Promoting lifestyle behaviors and related risk factors among female employees in the Zagazig City through the following objectives:

1) Assess the health promoting lifestyle behaviors among female employees.

2) Screen the presence of chronic illnesses affecting health, specifically hypertension, diabetes mellitus (DM), and obesity.

3) Explore the relationship between the healthy promoting lifestyle and the presence of chronic illnesses e.g., hypertension, diabetes mellitus, and obesity.

4) Determine the relationship between healthy promoting lifestyle and participants' personal characteristics, e.g. age, marital status, income, family size and residence.

5) Raise the participant's knowledge regarding the healthy lifestyle by distributing pamphlets and oral discussion with participants.

\section{Subjects and methods}

\subsection{Study design}

A cross sectional research design was selected to achieve the aim of the current study. 


\subsection{Setting}

The study was carried out on females employed at the governorate building in Zagazig City.

\subsection{Sample}

The study sample is a convenience sample of 200 females recruited from Zagazig Governorate administrative building. The inclusion criteria included females, aged 25 to 55, working in any administrative department for any duration and willing to participate in the study. The exclusion criteria were females not suffering from hypertension, diabetes mellitus. Sample Size was calculated by a personal computer to be 180 , provided that the total number of females employed in governorate building is 350 and the expected frequency of them in following health promoting lifestyle is $40 \%$ and the worst acceptable frequency is $35 \%$ with confidence level 95 .The researcher added $10 \%$ for drop outs, therefore the study sample included 200 females. The computer program was EPI-INFO statistical program version 6.04.

\subsection{Tools of data collection}

Two tools were used to collect data:

A self-administered questionnaire: It included a section for respondents' personal data as age, marital status, family size, residence, income, and history of diseases (diabetes, hypertension, etc.). This was followed by the Health-Promoting Lifestyle Profile scale - HPLP, an instrument developed by Walker et al. ${ }^{[10]}$ to determine healthy lifestyle behaviors. The HPLP assesses the individual's health-promoting attitudes and behaviors related to healthy lifestyle. The scale has a total of 48 items with 6 dimensions (e.g. Health responsibility, physical activity, nutrition, self actualization, interpersonal relationships, and stress management). All the items of the healthy lifestyle behavior scale are of positive presentation, there are no reversed items. Answers are on a Likert scale 1 as "Never", 2 as "Frequently, 3 as "Almost" and 4 as "Always". The higher the score the higher health-promoting level of behavior.

The total items of the HPLP is 48, which represents a high level of healthy lifestyles and health promotion. The six dimensions are subscales and include the following items: health responsibility (10), Physical activity (5), nutrition (6), self actualization (13), interpersonal relationships (7) and, stress management (7). The tool was reviewed by a group of experts in medical and nursing for face and content validity. Using a 3-point response format (e. g. $1=$ poor, $2=$ good, $3=$ excellent). Coefficient indicates the reliability of the scale $(r=0.92)$ : alpha coefficient reliability of the subscales varied from $r=0.70$ to $r=0.90$.

A Physical Examination Tool was devised to document systolic and diastolic blood pressure by sphygmomanometer, fasting blood sugar using Glucosure Star, weight of standard weight scale and height using tape scale (to the nearest $0.5 \mathrm{~cm}$ ). Body mass index is calculated using the equation: weight in $\mathrm{kg} /$ height in meters squared. The tools were finalized after modifications were done based on experts' suggestions. These included adding some probing questions, and re-wording of some phrases.

\subsection{Pilot study}

A pilot study was conducted on 20 female workers selected from the same study setting that represent $10 \%$ of the total sample to evaluate the clarity and applicability of the tools, as well as to estimate the time needed for data collection. No modifications were recommended, and those were not included in the main study sample.

\subsection{Ethical considerations}

Permission to conduct the study was obtained from the Human Research Ethics Committee. Participants were informed that anonymity and confidentiality would be maintained at all times. Subjects were encouraged to ask questions prior to enrolling in this study. Subjects were reassured that participation in this study is entirely voluntary and that they may withdraw from the study at any time. In addition, the participants were reassured that the data would be used only for the purpose of scientific research. The study maneuvers were of minimal risk to the participants: skin puncture was done under standard aseptic conditions for infection control. 
Fieldwork: After obtaining official approvals, the researchers started the process of selection of the participants according to the previously set criteria. Once the study has been explained to subjects, including the objectives, time commitment and process, subjects are given the self-administered questionnaire upon oral consent to participate in the study. The researchers were present all the time for any clarification. After filling in the questionnaire form, a physical examination was done for each participant. Skin puncture was made for obtaining a drop of blood for blood sugar test under standard aseptic conditions. Some anthropometric measurements were done, including height and weight. Height was measured to the nearest $0.5 \mathrm{~cm}$ without shoes using a tape measure, standing straight and looking straight ahead. Weight was measured without shoes and excess clothing to the nearest $0.1 \mathrm{~kg}$ using a weighing scale. Body mass index was categorized into three groups: (i) normal $<25 \mathrm{~kg} / \mathrm{m}^{2}$; (ii) overweight $\geq 25-<30 \mathrm{~kg} / \mathrm{m}^{2}$; and (iii) obese $\geq 30 \mathrm{~kg} / \mathrm{m}^{2}$.

Furthermore, blood pressure measurements were performed in a seated position after rest for $\geq 5$ minutes using a mercury blood pressure monitor, a cuff of suitable size was applied on the participant's exposed upper arm. Hypertension was defined as the proportion of participants having a blood pressure $\geq 140 / 90 \mathrm{mmHg}$.

An educational material (pamphlets) that focus on healthy lifestyle in diabetes, hypertension and obesity were distributed under the study sample for health education and oral discussion about these illnesses was allowed with the researchers. Two to three days weekly were scheduled to meet the study participants and time spent with each one ranged from 20 to 30 minutes. The fieldwork lasted for three months, during the period from the beginning of April to the end of June 2013.

Statistical design: Data were analyzed by computing using SPSS version 20. The methods used were percentage, mean and standard deviation for data description. Student's t test, Chi squared test, ANOVA test and Pearson's correlation test were used for finding significant differences and relations between variables. The results were considered significant at $p$ $\leq .05$.

\section{Results}

More than two thirds of the studied sample (68\%) were in the age group from $25-<50$, with a mean age of $44.27 \pm 9.71$. The majority of them (78.5\%) was married. Almost half of the studied sample (50.5\%), their family size ranged from 2 to 4 members. About half of them (46.5\%) their income was insufficient.

Screening of study women for chronic illnesses (DM, hypertension, and obesity) Table 1 reveals that one fifth of the studied sample (20\%) were hypertensive $(\geq 140 / 90)$, while $26 \%$ of them were diabetics $(>120)$ fasting blood sugar, and $68.5 \%$ were obese $(\geq 30)$ body mass index percent.

Figure 1 illustrates that the participants got good scores on self actualization domain (64\%), nutrition (64.5\%) and interpersonal relationship domain (57.5\%). However, they got poor scores on health responsibility (37.5\%), stress (26.5\%), and exercise (70.5\%).

Figure 2 clarifies that more than quarter of the studied sample (28\%) had one chronic disease (either DM or hypertension or obesity), while $19 \%$ of them had two to three chronic diseases.

Table 2 compares mean score of the different domains in relation to DM. Study result reveals that although the diabetic group recorded poorer scores on exercise $(71.2 \%)$, stress $(28.8 \%)$ and health responsibility $(40.4 \%)$ than the non diabetic group, $(70.3 \%, 25.7 \%, \& 36.5 \%$ respectively) but the difference was not statistically significant between both groups.

Comparison of the health promoting lifestyle between obese and non-obese cases, the study results showed no statistically significant differences. Obese women got poorer scores on stress management, (27.7\%), exercise (72.3\%), and health responsibility (35.8\%) respectively compared to the non-obese (see Table 3 ). 
Table 4 shows that the hypertensive group got poorer scores on stress management, (30\%), exercise (77.5\%), and health responsibility (47.5\%) than the other group. The study results pointed to no statistically significant differences were found between both studied groups.

Concerning correlations between personal characteristics and health promoting lifestyle Table 5 shows that there were a statistically significant negative correlation between age and exercise and stress $(r=-0.16, p<.05 \& r=-0.13, p<.05)$. Additionally, statistically significant negative correlation between income and overall life style domain scores $(r=-0.12, p$ $<.05)$. A statistically significant negative correlation was found between marital status and overall lifestyle $(r=-0.15, p$ $<.05)$.

Table 1. Screening of study women for chronic illnesses (DM, hypertension and obesity)

\begin{tabular}{|c|c|c|}
\hline Variables & No. & $\%$ \\
\hline $\begin{array}{r}\text { Blood pressure } \\
\text { Hypotension }\end{array}$ & 10 & 5 \\
\hline Normal blood pressure & 150 & 75 \\
\hline Hypertension & 40 & 20 \\
\hline \multicolumn{3}{|l|}{ Fasting blood sugar } \\
\hline$<120$ & 148 & 74 \\
\hline $120-$ & 32 & 16 \\
\hline $180-$ & 10 & 5 \\
\hline$>240$ & 10 & 5 \\
\hline Min. -Max & $70-400$ & \\
\hline Mean \pm SD & $113.56 \pm 59.23$ & \\
\hline \multicolumn{3}{|l|}{ Weight (in $\mathrm{Kg}$ ) } \\
\hline Min. -Max & $47-130$ & \\
\hline Mean \pm SD & $84.6 \pm 15.07$ & \\
\hline \multicolumn{3}{|l|}{ Height } \\
\hline Min. -Max & $125-196$ & \\
\hline Mean \pm SD & $160.49 \pm 8.48$ & \\
\hline \multicolumn{3}{|l|}{ Body mass index $\%$} \\
\hline$<25$ & 17 & 8.5 \\
\hline $25-<30$ & 46 & 23 \\
\hline$\geq 30$ & 137 & 68.5 \\
\hline Min.-Max & $18.83-55.42$ & \\
\hline Mean \pm SD & $23.98 \pm 6.15$ & \\
\hline
\end{tabular}

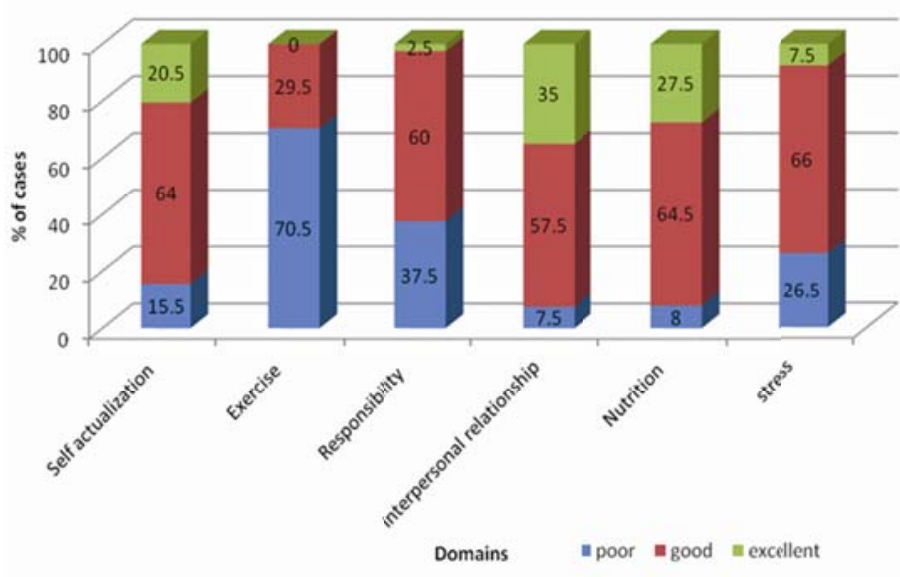

Figure 1. Distribution of women in the study group in relation to lifestyle domains

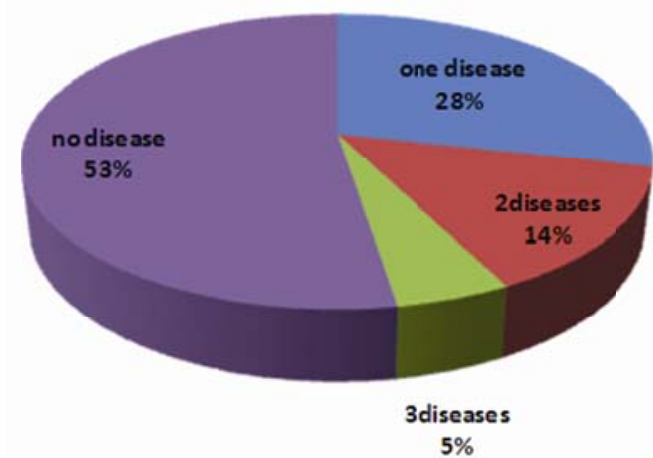

Figure 2. Distribution of cases in relation to presence of chronic diseases 
Table 2. Mean score of the different domains in relation to diabetes mellitus

\begin{tabular}{|c|c|c|c|c|c|c|}
\hline \multirow{2}{*}{ Variables } & \multicolumn{2}{|c|}{ Diabetic cases (52) } & \multicolumn{2}{|c|}{ Non diabetic cases (148) } & \multirow{2}{*}{ test } & \multirow{2}{*}{$p$} \\
\hline & No. & $\%$ & No. & $\%$ & & \\
\hline Self actualization domain (total score 52) & $31.65 \pm 6.87$ & & $32.95 \pm 7.75$ & & $t=1.06$ & .2867 \\
\hline Poor & 9 & 17.3 & 22 & 14.8 & & \\
\hline Good & 36 & 69.2 & 92 & 62.2 & $\chi^{2}=2.15$ & .3418 \\
\hline Excellent & 7 & 13.5 & 34 & 23 & & \\
\hline Health responsibility domain (total score 40 ) & $11.39 \pm 3.44$ & & $11.38 \pm 3.07$ & & $t=0.01$ & .9886 \\
\hline Poor & 21 & 40.4 & 54 & 36.5 & & \\
\hline Good & 28 & 53.8 & 92 & 62.2 & $\chi^{2}=3.6$ & .1650 \\
\hline Excellent & 3 & 5.8 & 2 & 1.4 & & \\
\hline Exercise domain (total score 20) & $8.4 \pm 2.47$ & & $8.65 \pm 2.47$ & & $t=0.61$ & .5391 \\
\hline Poor & 37 & 71.2 & 104 & 70.3 & & \\
\hline Good & 15 & 28.8 & 44 & 29.7 & $\chi^{2}=0.01$ & .9043 \\
\hline Excellent & 0 & 0 & 0 & 0 & & \\
\hline Interpersonal relationship (total score 28 ) & $19.58 \pm 4.23$ & & $19.58 \pm 4.43$ & & $t=0.01$ & .9953 \\
\hline Poor & 3 & 5.8 & 12 & 8.1 & & \\
\hline Good & 31 & 59.6 & 84 & 56.8 & $\chi^{2}=0.34$ & .8443 \\
\hline Excellent & 18 & 34.6 & 52 & 35.1 & & \\
\hline Nutrition(total score 24) & $16.81 \pm 3.79$ & & $16.27 \pm 3.59$ & & $t=0.92$ & .3610 \\
\hline Poor & 4 & 7.7 & 12 & 8.1 & & \\
\hline Good & 32 & 61.5 & 97 & 65.5 & $\chi^{2}=0.38$ & .8282 \\
\hline Excellent & 16 & 30.8 & 39 & 26.4 & & \\
\hline Stress (total score 28) & $15.33 \pm 3.34$ & & $16.13 \pm 3.77$ & & $t=1.36$ & .1761 \\
\hline Poor & 15 & 28.8 & 38 & 25.7 & & \\
\hline Good & 35 & 67.3 & 97 & 65.5 & $\chi^{2}=1.42$ & .4928 \\
\hline Excellent & 2 & 3.8 & 13 & 8.8 & & \\
\hline
\end{tabular}

Table 3. Mean score of the different domains in relation to obesity

\begin{tabular}{|c|c|c|c|c|c|c|}
\hline \multirow[t]{2}{*}{ Variables } & \multicolumn{2}{|c|}{$\begin{array}{l}\text { Non obese cases }(\mathrm{BMI}<30 \%) \\
(\mathrm{n}=63)\end{array}$} & \multicolumn{2}{|c|}{$\begin{array}{l}\text { Obese cases }(\mathrm{BMI} \geq 30 \%) \\
(\mathrm{n}=137)\end{array}$} & \multirow[t]{2}{*}{ test } & \multirow[t]{2}{*}{$p$} \\
\hline & No. & $\%$ & No. & $\%$ & & \\
\hline Self-actualization domain (total score 52) & $32.25 \pm 8.15$ & & $32.78 \pm 7.26$ & & $t=0.46$ & .6485 \\
\hline Poor & 12 & 19 & 19 & 13.9 & & \\
\hline Good & 40 & 63.5 & 88 & 64.2 & $\chi^{2}=1.17$ & .5584 \\
\hline Excellent & 11 & 17.5 & 30 & 21.9 & & \\
\hline Health responsibility domain (total score 40 ) & $20.52 \pm 4.96$ & & $21.25 \pm 1.99$ & & $t=0.96$ & .3405 \\
\hline Poor & 26 & 41.3 & 49 & 35.8 & & \\
\hline Good & 36 & 57.1 & 84 & 61.3 & $\chi^{2}=0.78$ & .6770 \\
\hline Excellent & 1 & 1.6 & 4 & 2.9 & & \\
\hline Exercise domain (total score 20) & $8.71 \pm 2.49$ & & $8.53 \pm 2.46$ & & $t=0.50$ & .6161 \\
\hline Poor & 42 & 66.7 & 99 & 72.3 & & \\
\hline Good & 21 & 33.3 & 38 & 27.7 & $\chi^{2}=0.65$ & .4201 \\
\hline Excellent & 0 & 0 & 0 & 0 & & \\
\hline Interpersonal relationship (total score 28) & $19.94 \pm 4.4$ & & $19.42 \pm 4.36$ & & $t=0.78$ & .0602 \\
\hline Poor & 6 & 9.5 & 9 & 6.6 & & \\
\hline Good & 34 & 54 & 81 & 59.1 & $\chi^{2}=0.76$ & 6833 \\
\hline Excellent & 23 & 36.5 & 47 & 34.3 & & \\
\hline Nutrition(total score 24) & $15.98 \pm 3.97$ & & $16.61 \pm 3.48$ & & $t=1.22$ & .2628 \\
\hline Poor & 8 & 12.7 & 8 & 5.8 & & \\
\hline Good & 39 & 61.9 & 90 & 65.7 & $\chi^{2}=2.78$ & .2488 \\
\hline Excellent & 16 & 25.4 & 39 & 28.5 & & \\
\hline Stress (total score 28) & $16.16 \pm 3.82$ & & $15.81 \pm 3.61$ & & $t=0.62$ & .5341 \\
\hline Poor & 15 & 23.8 & 38 & 27.7 & & \\
\hline Good & 41 & 65.1 & 91 & 66.4 & $\chi^{2}=1.86$ & .3941 \\
\hline Excellent & 7 & 11.1 & 8 & 5.8 & & \\
\hline
\end{tabular}


Table 4. Mean score of the different domains in relation to hypertension

\begin{tabular}{|c|c|c|c|c|c|c|c|c|}
\hline \multirow[t]{2}{*}{ Variables } & \multicolumn{2}{|c|}{$\begin{array}{l}\text { hypotension cases } \\
(n=10)\end{array}$} & \multicolumn{2}{|c|}{$\begin{array}{l}\text { Normal pressure } \\
\text { cases }(n=150)\end{array}$} & \multicolumn{2}{|c|}{$\begin{array}{l}\text { Hypertension } \\
\text { cases }(n=40)\end{array}$} & \multirow[t]{2}{*}{ test } & \multirow[t]{2}{*}{$p$} \\
\hline & No. & $\%$ & No. & $\%$ & No. & $\%$ & & \\
\hline Self-actualization domain (total score 52) & \multicolumn{2}{|c|}{$33 \pm 8.29$} & \multicolumn{2}{|c|}{$32.82 \pm 7.45$} & \multicolumn{2}{|c|}{$31.75 \pm 7.79$} & $F=0.33$ & .7202 \\
\hline Poor & 2 & 20 & 21 & 14 & 8 & 20 & & \\
\hline Good & 6 & 60 & 99 & 66 & 23 & 57.5 & $\chi^{2}=1.35$ & .8526 \\
\hline Excellent & 2 & 20 & 30 & 20 & 9 & 22 & & \\
\hline $\begin{array}{l}\text { Health responsibility domain (total score } \\
\text { 40) }\end{array}$ & \multicolumn{2}{|c|}{$12.5 \pm 4.28$} & \multicolumn{2}{|c|}{$11.44 \pm 3.06$} & \multicolumn{2}{|c|}{$10.93 \pm 3.27$} & $F=1.05$ & .3405 \\
\hline Poor & 2 & 20 & 54 & 36 & 19 & 47.5 & & \\
\hline Good & 7 & 70 & 93 & 62 & 20 & 50 & $\chi^{2}=5.3$ & .2572 \\
\hline Excellent & 1 & 10 & 3 & 2 & 1 & 2.5 & & \\
\hline Exercise domain (total score 20) & \multicolumn{2}{|c|}{$8.6 \pm 2.12$} & \multicolumn{2}{|c|}{$8.66 \pm 2.49$} & \multicolumn{2}{|c|}{$8.3 \pm 2.48$} & $F=0.43$ & .7158 \\
\hline Poor & 7 & 70 & 103 & 68.7 & 31 & 77.5 & & \\
\hline Good & 3 & 30 & 47 & 31.3 & 9 & 22.5 & $\chi^{2}=1.19$ & .5526 \\
\hline Excellent & 0 & 0 & 0 & 0 & 0 & 0 & & \\
\hline Interpersonal relationship (total score 28 ) & \multicolumn{2}{|c|}{$20.9 \pm 3.41$} & \multicolumn{2}{|c|}{$19.53 \pm 4.42$} & \multicolumn{2}{|c|}{$19.45 \pm 4.44$} & $F=0.48$ & .6179 \\
\hline Poor & 0 & 0 & 12 & 8 & 3 & 7.5 & & \\
\hline Good & 7 & 70 & 86 & 57.3 & 22 & 55 & $\chi^{2}=1.26$ & .8675 \\
\hline Excellent & 3 & 30 & 52 & 34.7 & 15 & 37.5 & & \\
\hline Nutrition(total score 24) & \multicolumn{2}{|c|}{$16.3 \pm 3.86$} & \multicolumn{2}{|c|}{$16.37 \pm 3.56$} & \multicolumn{2}{|c|}{$16.6 \pm 3.98$} & $F=0.06$ & .9333 \\
\hline Poor & 1 & 10 & 13 & 8.7 & 2 & 5 & & \\
\hline Good & 7 & 70 & 95 & 63.3 & 27 & 67.5 & $\chi^{2}=0.93$ & .9193 \\
\hline Excellent & 2 & 20 & 42 & 28 & 11 & 27.5 & & \\
\hline Stress (total score 28) & \multicolumn{2}{|c|}{$16.1 \pm 3.18$} & \multicolumn{2}{|c|}{$16.1 \pm 3.73$} & \multicolumn{2}{|c|}{$15.2 \pm 3.54$} & $F=0.96$ & .5341 \\
\hline Poor & 3 & 30 & 38 & 25.3 & 12 & 30 & & \\
\hline Good & 7 & 70 & 98 & 65.3 & 27 & 67.5 & $\chi^{2}=3.11$ & .5390 \\
\hline Excellent & 0 & 0 & 14 & 9.3 & 1 & 2.5 & & \\
\hline
\end{tabular}

Table 5. Correlation between domain's score and personal characteristics

\begin{tabular}{llllllll}
\hline Variable & Self-actualization & Exercise & Responsibility & $\begin{array}{l}\text { Interpersonal } \\
\text { relationship }\end{array}$ & Nutrition & Stress & $\begin{array}{l}\text { Total } \\
\text { domains }\end{array}$ \\
\hline Age & -0.06 & $-0.16^{*}$ & -0.03 & -0.10 & $0.12^{*}$ & $-0.13^{*}$ & -0.07 \\
Marital & $-0.13^{*}$ & $-0.16^{*}$ & $-0.12^{*}$ & -0.08 & -0.08 & $-0.15^{*}$ & $-0.15^{*}$ \\
Family size & $0.18^{*}$ & $-0.18^{*}$ & 0.05 & $0.16^{*}$ & 0.11 & 0.03 & 0.11 \\
Income & $-0.14^{*}$ & -0.07 & -0.05 & -0.10 & -0.08 & -0.06 & $-0.12^{*}$ \\
Residence & -0.06 & -0.04 & 0.03 & -0.05 & 0.02 & -0.01 & -0.03 \\
\hline
\end{tabular}

${ }^{*} p<.05$ significant correlation

\section{Discussion}

Most of the chronic illnesses that are of large numbers are related to adverse lifestyle. The need for lifestyle change is therefore of great importance in reducing the prevalence of these conditions and the resultant burden ${ }^{[4]}$.

Screening for the prevalence of chronic illnesses among the studied sample clarified that more than two thirds of the studied sample was overweight and obese, one fifth of them had hypertension, and one quarter had diabetes mellitus. These results might be due to poor access to health facilities, poverty (half of the study sample their income was insufficient), and high costs of drugs. In the same way Nugent ${ }^{[6]}$ reported that chronic illnesses are increasing in global prevalence and seriously threaten the developing nations' ability to improve the health of their populations. In this respect, Ibrahim and Damasceno ${ }^{[11]}$ emphasized that the health system in many developing countries is inadequate because of low funds, poor infrastructure, and lack of experience. 
Furthermore, the study results clarified that nearly one fifth of the study sample had two to three chronic illnesses. Similarly, Earl et al. ${ }^{[3]}$ Mentioned that analysis of recent national data, which shows that about 1 in 7 adults had at least 2 of 5 chronic conditions associated with disease and death, helps to address a gap in the existing knowledge base.

As regards the health promoting lifestyle among female employees, results revealed that the studied sample got the highest scores on self-actualization, interpersonal relationships, and nutrition. These results might be due to that all the studied sample are employees, therefore they build good relationships with others and try to achieve the sense of selfActualization. Moreover, having a job and a regular income may influence self-respect. Furthermore, these results reflected the Egyptian culture in giving support to each other during ease and difficult time. In accordance with these results Al-Maaitah ${ }^{[12]}$ investigating health promoting behaviors of Jordanian Muslim women found that the women got high scores of self-actualization, interpersonal support and nutrition. Moreover Tokgöz ${ }^{[13]}$ in her study on 282 female lecturers discovered that self-actualization and interpersonal support scores were the highest.

On the other hand, the current study results found that the participants got poorest scores on exercise, stress, and health responsibility. The low scores of stress management may be explained by participants in this current study commonly experienced stress and have indicated that they were not confident in their ability to manage the stress in their lives. The lowest ranking in relation to incorporation of physical activity into their lifestyle may have been influenced by Egyptian culture and social structure or characteristics of the studied sample. Additionally, health responsibility involves an active sense of accountability for one's own well-being. It includes paying attention to one's own health. Naturally, if an individual does not perceive his/her health problems, he/she does not make an effort to promote his/her health. Similarly, a study done by Ays et al. ${ }^{[14]}$ revealed that, the participants got the lowest mean scores on exercise and health responsibility and stress management.

Comparison between those who have chronic diseases and don't, the study results pointed to that, the former got poorer scores on exercise, health responsibility and stress than the later one. This indicates a general lack of knowledge among the participants that the increase of the disease incidence rates is due in part to unhealthy lifestyle are contributory factors to the high risk of chronic illnesses. Peacey et al. ${ }^{[15]}$ supported the researchers point of view regarding the influence of lifestyle on the health problems and they found a low knowledge, even among the well-educated young peoples, especially in some countries of Eastern Europe, Asia, Africa and Latin America.

Despite a strong link between physical inactivity and chronic illness risk, a growing body of evidence originating from representative samples found that a low percentage of adults identified a lack of physical activity as a risk factor for the diseases. The results of study have revealed that regular physical activity is widely recognized as a mean of preventing the occurrence of many chronic diseases and reduced risk of all-cause mortality ${ }^{[16]}$. Recent evidence confirms the previous findings that engaging in moderate physical activity is very important for the primary prevention of chronic diseases ${ }^{[17]}$.

Very interesting are the previously published data from 30 articles evaluated by Oguma and Shinoda-Tagawa ${ }^{[18]}$. The results indicated that physical activity was associated with significant reduction of chronic heart disease and stroke and hypertension among women respectively. Concerning the significant role of exercise in decreasing the risk of diabetes mellitus was also found in a recent paper by Grace et al. ${ }^{[19]}$.

Protective effects of physical activity in overweight and obesity are well documented by Jethon and WierzbickaDamska $^{[20]}$. The authors concluded that physical exertion without the help of diet is moderately effective in reduction of a body weight among overweight or obese individuals.

Physical health outcomes related to stress included hypertension as mentioned by Din-Dzietham et al. ${ }^{[21]}$. Furthermore, the biological responses resulting from stress are possible contributors to the development of a number of physiological risk factors for cardiovascular disease, stroke, type 2 diabetes and several cancers ${ }^{[22]}$. 
A meta-analysis of longitudinal studies on stress and adiposity also found that stress is associated with increasing adiposity ${ }^{[23]}$. A systematic review of the literature reported less healthy eating patterns and higher body weight in individuals in lower social positions who had higher stress levels, with these patterns more apparent in women than men ${ }^{[24]}$.

Concerning the correlation between personal characteristics and promoting healthy lifestyle, study results clarified that there were a statistically significant negative correlations between age and exercise and stress. The youngest is the age, the higher is the promoting lifestyle behaviors in exercise and stress management. On the contrary Pirincci et al. ${ }^{[25]}$ found that as age increased, HPLP score rose accordingly, and this association was statistically significant. Academic staff aged 40 years or more had a high HPLP score, as age increased, exercise and stress management scores also increased.

The study results showed that there was a statistically significant negative correlation between income and overall life style domains score. The higher is the income, the lower will be the life style healthy score. This result might be due to that individuals of high standard usually adopt poor lifestyle habits and behaviors as eating fast foods, always riding cars, and using elevators. On the contrary Ays et al. ${ }^{[14]}$ found a statistically significant difference between income and HPLP scores. The workers with an income higher than their expenses received higher HPLP scores.

Furthermore, this study result pointed to a statistically significant negative correlation found between marital status and overall lifestyle. However, Tokgöz ${ }^{[13]}$ found no relation between marital status and overall scores of HPLP and subscales.

Recently, a study done in Turkey by Hacer et al. ${ }^{[26]}$ found that there was no statistically significant variation when evaluated for age, marital status, family type, and economic status.

\section{Conclusion}

Results from this study suggest that participants do not consistently include health-promoting behaviors into their lifestyle, especially exercise, health responsibility and prevention of stress. About one fifth of the study sample was hypertensive, while one quarter of them was diabetic, and the majority was overweight and obese. There were no statistically significant relations between chronic illnesses (hypertension, diabetes and obesity) and promoting life style behaviors among female employees in Zagazig City.

\section{Recommendations}

Develop a process to promote worksite wellness programs, to complete health assessments, and to support behavioral changes intended to promote healthy lifestyles.

\section{References}

[1] Kickbusch I. The contribution of the World Health Organization to a new public health and health promotion. American J of Public Health. 2003; 93: 383-8. http://dx.doi.org/10.2105/AJPH.93.3.383

[2] Pender N, Barkauskas V, Hayman L. Health promotion and disease prevention: Toward excellence in nursing practice and education. Nursing Outlook. 1992; 40: 106-12.

[3] Earl S.Janet B. Samuel F.Richard A. Wayne H. Co-occurrence of leading lifestyle-related chronic conditions among adults in the United States, 2002-2009, 2013, 10, 25, pp1-12.

[4] Pang J. \& Lee G. Epidemiology of chronic diseases and need for lifestyle advices, Hesingapore Family physician. $2012 ; 38(3)$ : p-8.

[5] Centers for Disease Control and Prevention. The power of prevention. Chronic disease the public health challenge of the 21st century, 2013. Available from: http:/www.cdc.gov/chronicdisease/pdf/2009-power-of-prevention.pdf. Accessed January 17.

[6] Nugent R. Chronic diseases in developing countries; health and economic burdens, New York Academy of Sciences. 2008; 1136: 70-79. 
[7] Moos M \& Bennett A. Preconceptional health promotion. In 'reducing racial/ethnic disparities in reproductive and perinatal Outcomes: The evidence from population-based interventions', (Eds) Handler A, Kennelly J, Peacock N. 2011; 65-92. http://dx.doi.org/10.1007/978-1-4419-1499-6_5

[8] Karasek R., Kawasaki N., Bongers P, Amick B: The job content questionnaire: an instrument for internationally comparative assessments of job characteristics. J Occupational Health Psychology. 1998; 3(4): 322-355. http://dx.doi.org/10.1037/1076-8998.3.4.322

[9] Harris, M. Strategic approaches to the development of Australia's future primary care workforce. Med J Aust. 2011; 194(11): S88-S91.

[10] Walker, S., Sechrist, K. \& Pender, N. The health-promoting lifestyle profile: Development and psychometric characteristics. Nursing Research. 1987; 36(2): 76-81. http://dx.doi.org/10.1097/00006199-198703000-00002

[11] Ibrahim M. \& Damasceno A. Hypertension in developing countries. Lancet. 2012; 380: 611-19. http://dx.doi.org/10.1016/S0140-6736(12)60861-7

[12] Al Ma'aitah R, Health promotion behaviors of Jordanian women. Health Care for Women International. 1999; 20 : 533-47. http://dx.doi.org/10.1080/073993399245449

[13] Tokgöz E. Evaluation of health behaviors among lecturers and affecting factors (Kadın ö g־ retim elemanlarının sa g` lı g־ 1 geli s, tirme davranı s, ları ve etkileyen etmenlerin de g־ erlendirilmesi). Dokuz Eylul University of Health Sciences Institute, an Unpublished PhD Thesis, Izmir (in Turkish), 2002.

[14] Ay s, E., Zuhal B. and Dilek B. Health promoting behaviors and factors related to lifestyle among Turkish workers and occupational health nurses' responsibilities in their health promoting activities. Industrial Health. 2007; 45: 151-159. http://dx.doi.org/10.2486/indhealth.45.151

[15] Peacey V, Steptoe A, Davidsdttir S, Baban A, Wardle J. Low levels of breast cancer risk awareness in young women: An international survey. Eur J Cancer. 2006; 42: 2585-9. http://dx.doi.org/10.1016/j.ejca.2006.03.017

[16] Lebrun C, van der Schouw Y, de Jong F, et al. Relations between body composition, functional and hormonal parameters and quality of life in healthy postmenopausal women. Maturitas. 2006; 55: 82-92. http://dx.doi.org/10.1016/j.maturitas.2006.01.008

[17] Kruk J. Physical activity in the prevention of the most frequent chronic diseases: an analysis of the recent evidence. Asian Pacific J Cancer Prev. 2007; 8: 325-338.

[18] Oguma Y, Shinoda-Togawa T. Physical activity decreases cardiovascular disease risk in women. Review and meta analysis. Am J Prev. 2004; 26: 407-18. http://dx.doi.org/10.1016/j.amepre.2004.02.007

[19] Grace S, Barry-Biandchi S, Stewart D. Physical activity behavior, motivational readiness and self-efficacy among Ontarians with cardiovascular disease and diabetes. J Behavior Med. 2007; 30: 21-9. http://dx.doi.org/10.1007/s10865-006-9080-5

[20] Jethon Z, Wierzbicka-Damska. Mozliwosciprzeciwdzialania powstawaniu nadwagi i otylosci zapomococzizycznych. In: Znaczenie Aktywnolci Ruchowejdla Zdrowia. Studia i Monografie AWF we Wroclawiu. 2005; 75: 83-103.

[21] Din-Dzietham, R., Nembhard, W., Collins, R., \& Davis, S. "Perceived stress following race-based discrimination at work is associated with hypertension in African-Americans. The metro Atlanta heart disease study, 1999-2001", Soc Sci.Med. 2004; 58: 449-461.

[22] O'Dea, K. \& Daniel, M., "How social factors affect health: Neuroendocrine interactions," in The Social Origins of Health and Well-being, R. Eckersley, J. Dixon, \& B. Douglas, (eds.), Cambridge University Press, Cambridge. 2001; 231-244.

[23] Wardle J, Chida Y, Gibson E, Whitaker K, Steptoe A. Stress and Adiposity: A Meta-analysis of longitudinal studies. Obesity. 2011; 19(4): 771-778. http://dx.doi.org/10.1038/oby.2010.241

[24] Moore C, Cunningham S. Social position, psychological stress, \& obesity: A systematic review. J Acad Nutrition Dietetics. 2012; 112(4): 518-526. http://dx.doi.org/10.1016/j.jand.2011.12.001

[25] Pirincci, E. Rahman, S. Durmusx A., Erdem, R. Factors affecting health-promoting behaviors in academic staff .Public Health. 2008; 122: 1261-1263. http://dx.doi.org/10.1016/j.puhe.2008.04.006

[26] Hacer S., Fevziye C., \& Melis N. Healthy lifestyle promoting behavior in Turkish women aged 18-64, Asian Pacific J Cancer Prev, 2012; 13: 1241-1245. http://dx.doi.org/10.7314/APJCP.2012.13.4.1241 